\title{
CAFÉ NO DIA A DIA
}

ANDERSON JUNGER TEODORO

RAQUEL BERNARDO NANA DE CASTRO

RODRIGO GONÇALVES GUSMÃO DE SOUZA

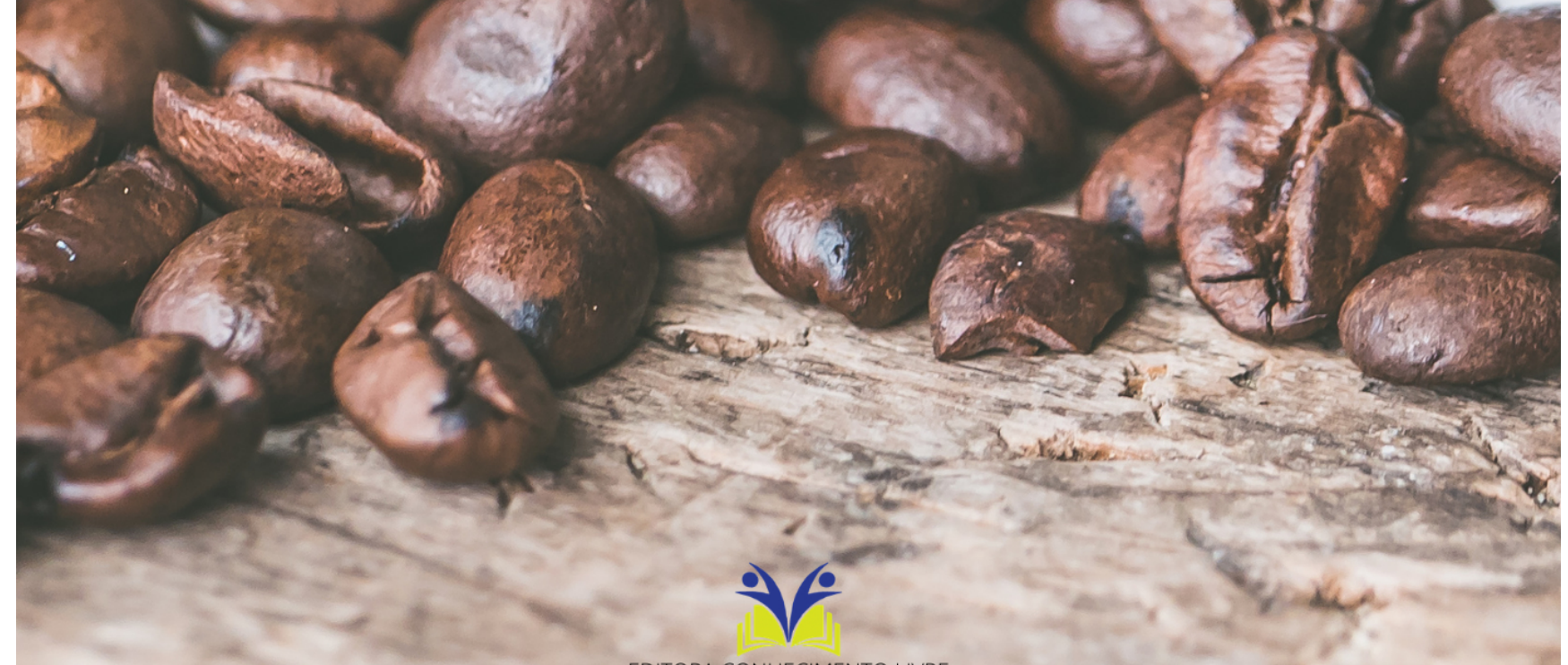


Anderson Junger Teodoro

Raquel Bernardo Nana de Castro

Rodrigo Gonçalves Gusmão de Souza

Café no dia a dia

$1^{\text {a }}$ ed.

Piracanjuba-GO

Editora Conhecimento Livre

Piracanjuba-GO 
$1^{\mathrm{a}} \mathrm{ed}$

\section{Dados Internacionais de Catalogação na Publicação (CIP)}

\section{Teodoro, Anderson Junger \\ T328C Café no dia a dia}

/ Anderson Junger Teodoro. Raquel Bernardo Nana de Castro. Rodrigo Gonçalves Gusmão de Souza. - Piracanjuba-GO

Editora Conhecimento Livre, 2021

38 f.: il

DOI: $10.37423 / 2021 . e d c 1229$

ISBN: 978-65-89145-69-1

Modo de acesso: World Wide Web

Incluir Bibliografia

1. café 2. antioxidante 3. torrefação 4. bebida I. Teodoro, Anderson Junger II. Castro, Raquel

Bernardo Nana de III. Souza, Rodrigo Gonçalves Gusmão de IV. Título

https://doi.org/10.37423/2021.edcl229

O conteúdo dos artigos e sua correção ortográfica são de responsabilidade exclusiva dos seus respectivos autores. 


\section{EDITORA CONHECIMENTO LIVRE}

\section{Corpo Editorial}

Dr. João Luís Ribeiro Ulhôa

Dra. Eyde Cristianne Saraiva-Bonatto

MSc. Anderson Reis de Sousa

$\underline{\text { MSc. Frederico Celestino Barbosa }}$

MSc. Carlos Eduardo de Oliveira Gontijo

MSc. Plínio Ferreira Pires

Editora Conhecimento Livre

Piracanjuba-GO 
Café no dia a dia
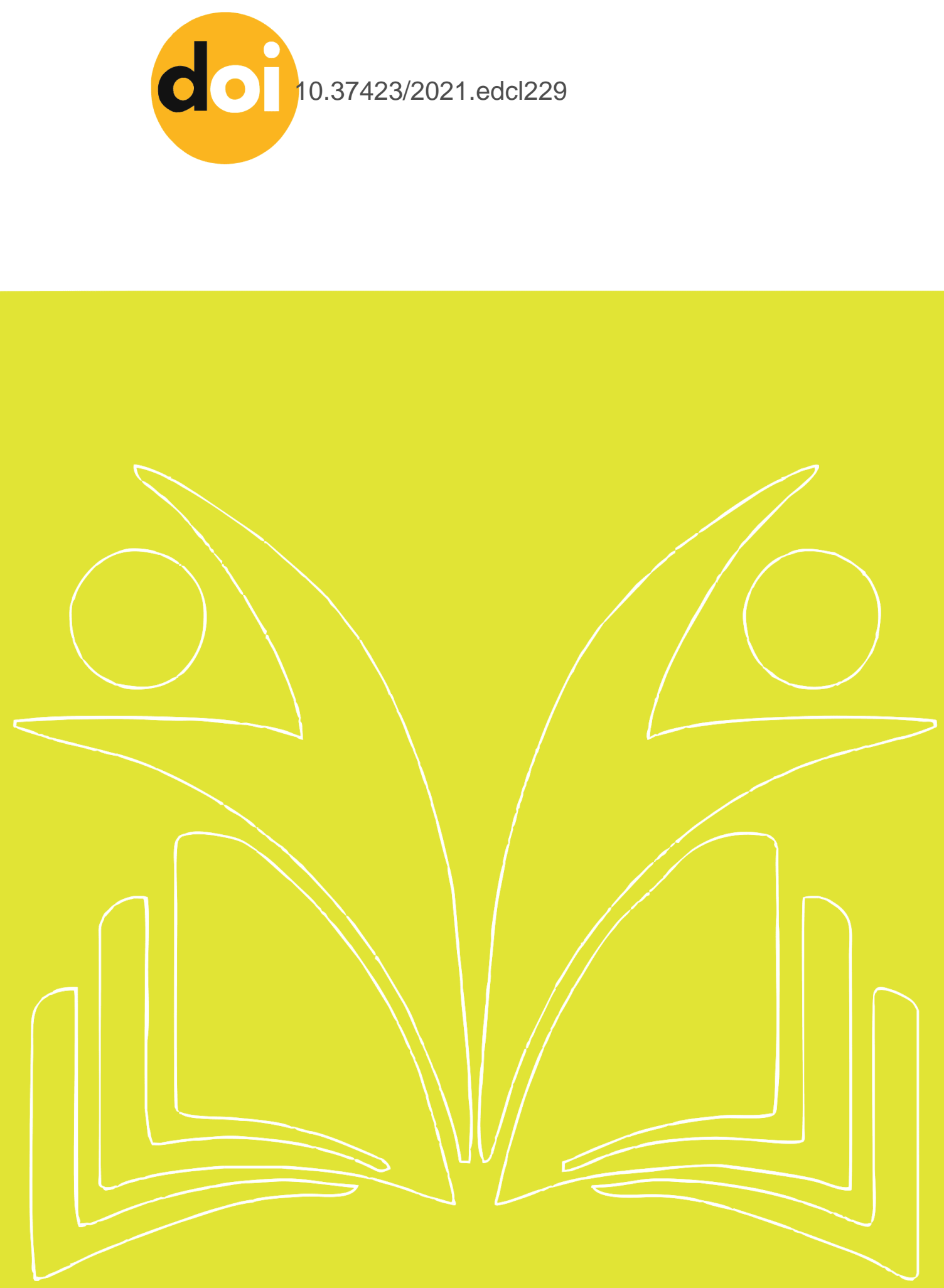


\section{GAFÉ NO DIAA DIA}

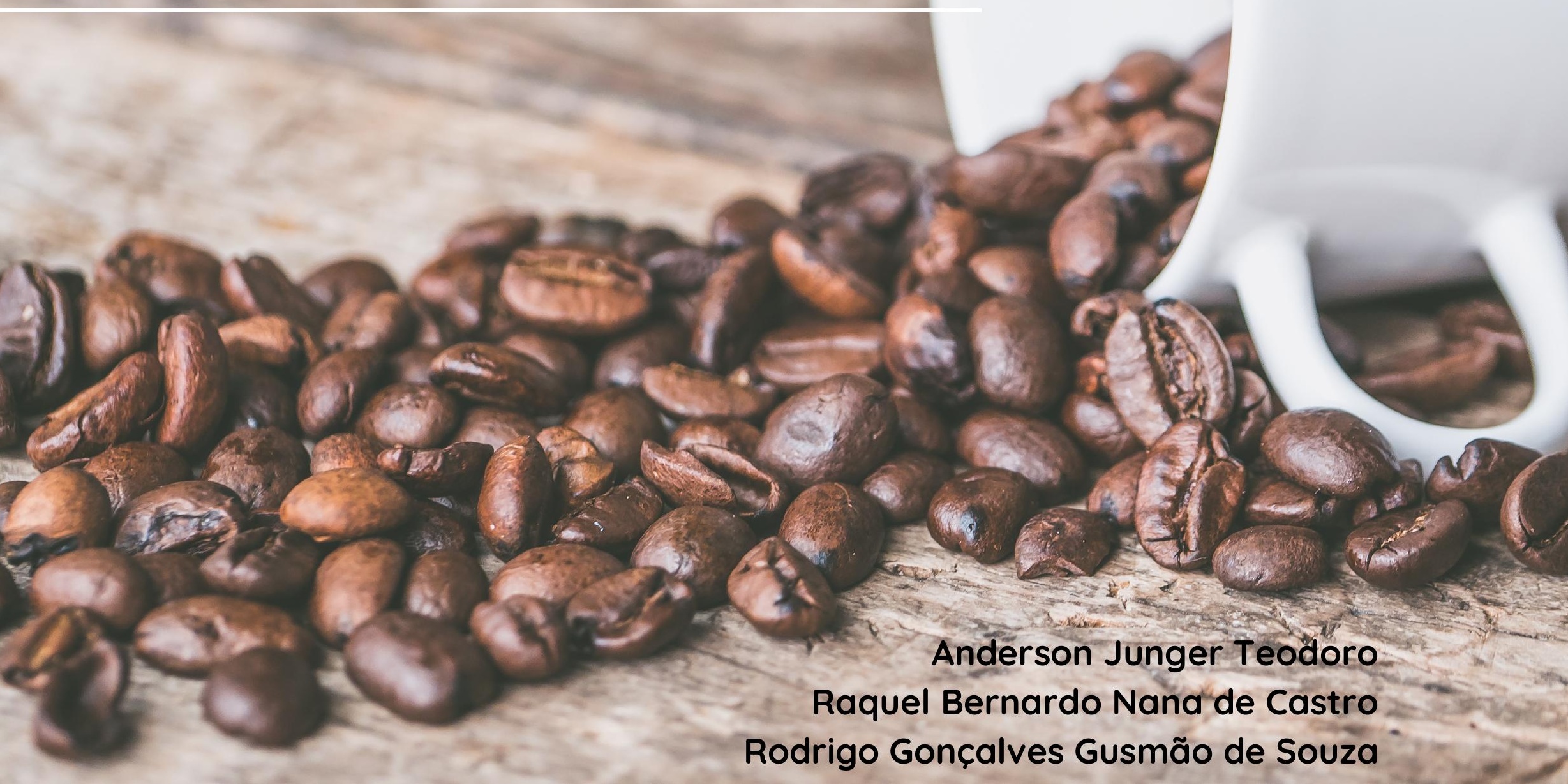


Universidade Federal do Estado do Rio de Janeiro

TEODORO, Anderson. CASTRO, Raquel. DE SOUZA, Rodrigo.

CAFÉ NO DIA A DIA / Anderson Junger Teodoro, Raquel Bernardo Nana de Castro, Rodrigo Gonçalves Gusmão de Souza - 1a Edição - Rio de Janeiro [RJ]: (Editora), 2021, 32p. 


\section{Apresentação}

Professor, cientista e especialista em alimentos e nutrição e seu grupo de pesquisa dedicado ao estudo de alimentos funcionais uniram-se para produzir um trabalho sobre a bebida nossa do nosso dia a dia. Esta pesquisa fornece ao público uma maneira mais simples de lembrar que por trás de cada gole e aroma contido numa xicara de café experienciamos uma história de tradição do consumo desta bebida que para além do prazer nos traz inúmeros benefícios à saúde.

Este ebook Café no dia a dia apresenta o complicado mundo do café numa linguagem simples e acessível, abordando os aspectos históricos do seu uso, plantio, elaboração da bebida, composição química e nutricional, consumo e benefícios à saúde.

O conhecimento deste ebook pode educar e influenciar a prática de consumo saudável, informando ao leitor/consumidor de café os benefícios reais que os antioxidantes e outros compostos bioativos presentes no café promovem à saúde. Assim estabelece as bases deste campo da ciência que continua a se expandir, mudando o relacionamento da sociedade moderna com o alimento. O café no dia a dia pode ajudar a nos manter ativos e de ganho proteger a nossa saúde. 


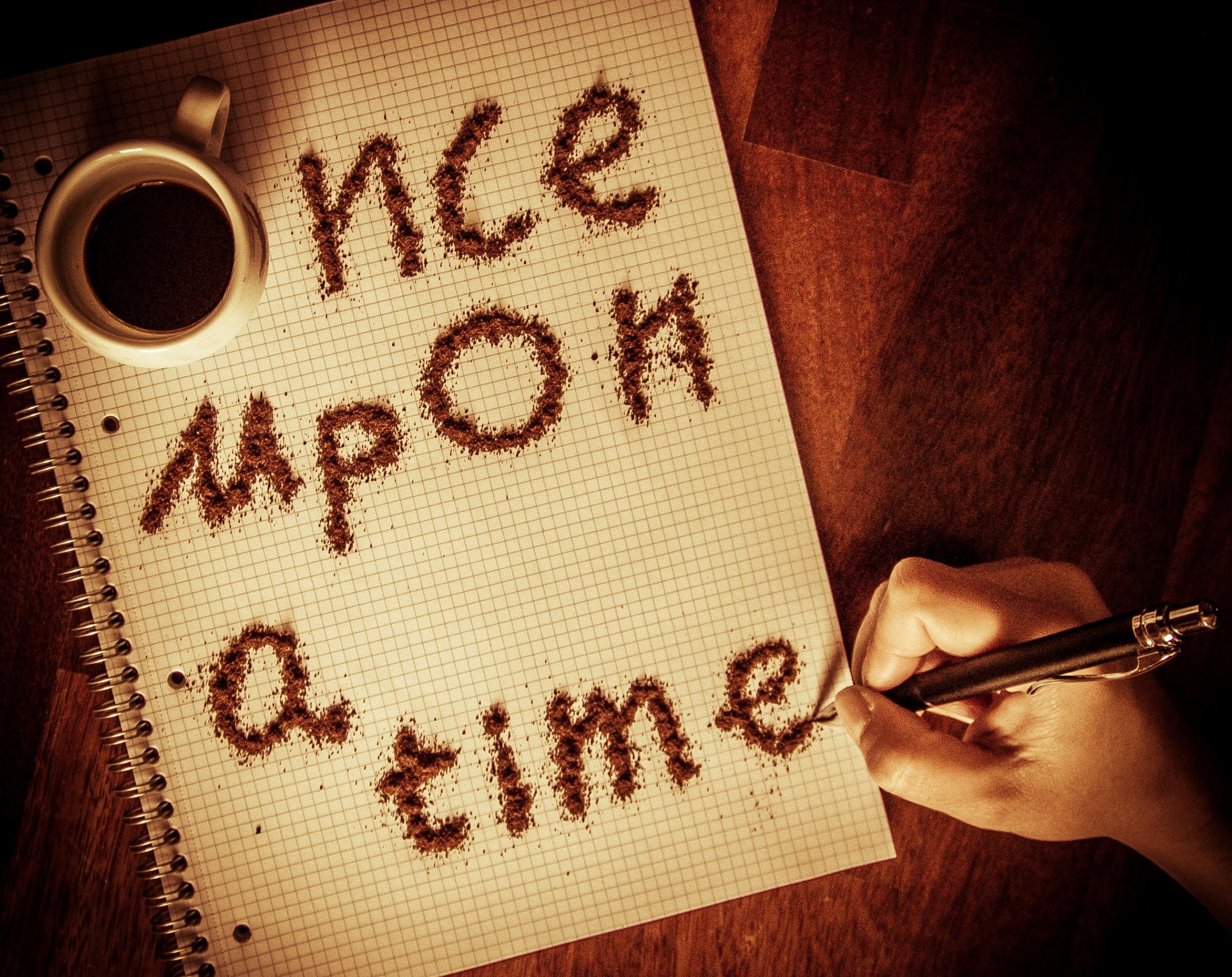




\section{Históría do café}

A origem do cafeeiro oriunda de uma região localizada no chifre da África, a Etiópia.

Nela, os etíopes consumiam a polpa doce, misturavam em banha durante as refeições ou ingeriam a polpa macerada. Também se produzia chá com as folhas do cafeeiro, assim como as mastigavam.

Além disso, também era feito um suco fermentado que se transformava em bebida alcoólica. 
Em 1727 as primeiras sementes de café chegaram ao Brasil através do oficial português Francisco de Mello de Palheta, vindo da Guiana Francesa, para o Pará.

O cultivo se adaptou melhor no Vale do Paraíba, de onde se difundiu para o sul de Minas Gerais, Paraná e São Paulo.

A partir da década de 1880 o café começou a permear o estado paulista, criando cidades e riquezas. No final do século XIX, O país controlava o mercador cafeeiro mundial. 


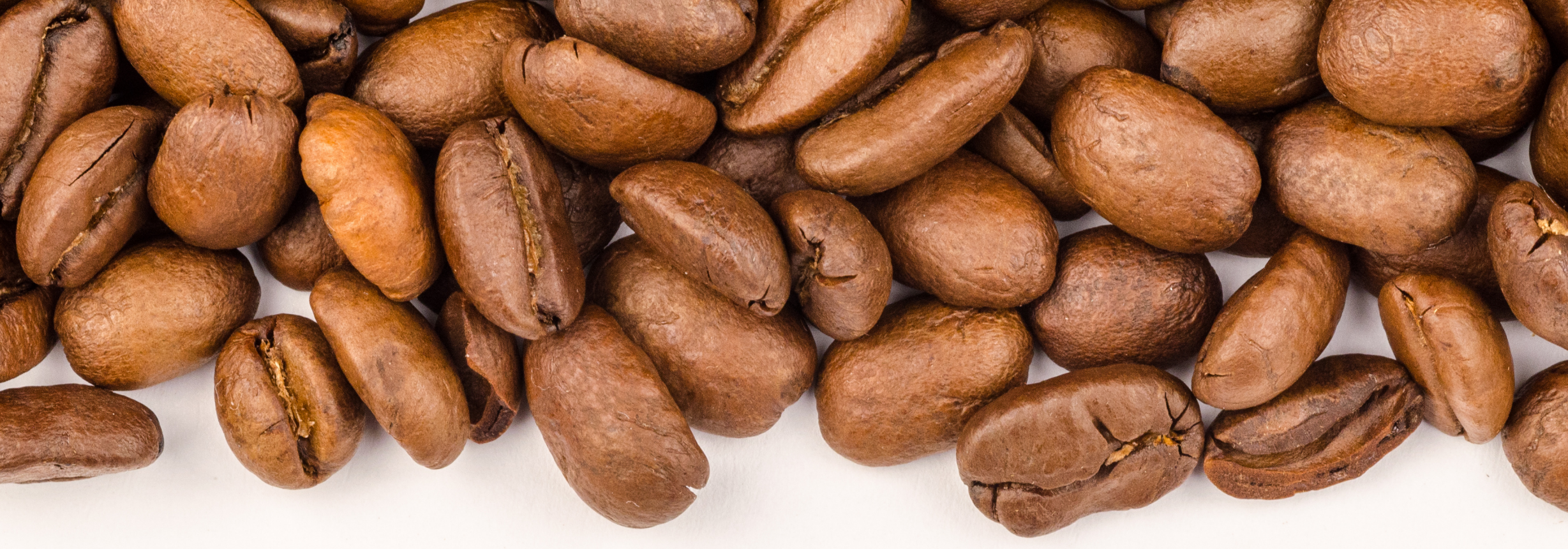

Tradicionalmente, o café é produzido no Brasil desde a época do império, com a mão-de-obra imigrante a cultura ganhou impulso e durante três quartos de século, quase toda riqueza do país se concentrou na agricultura cafeeira.

Durante toda sua história, tem sido uma importante fonte de renda para a economia do país e contribuindo para o PIB (Produto Interno Bruto) do Brasil. 


\section{FLUXOGRAMA DAS FASES DE CULTIVO DO CAFÉ}

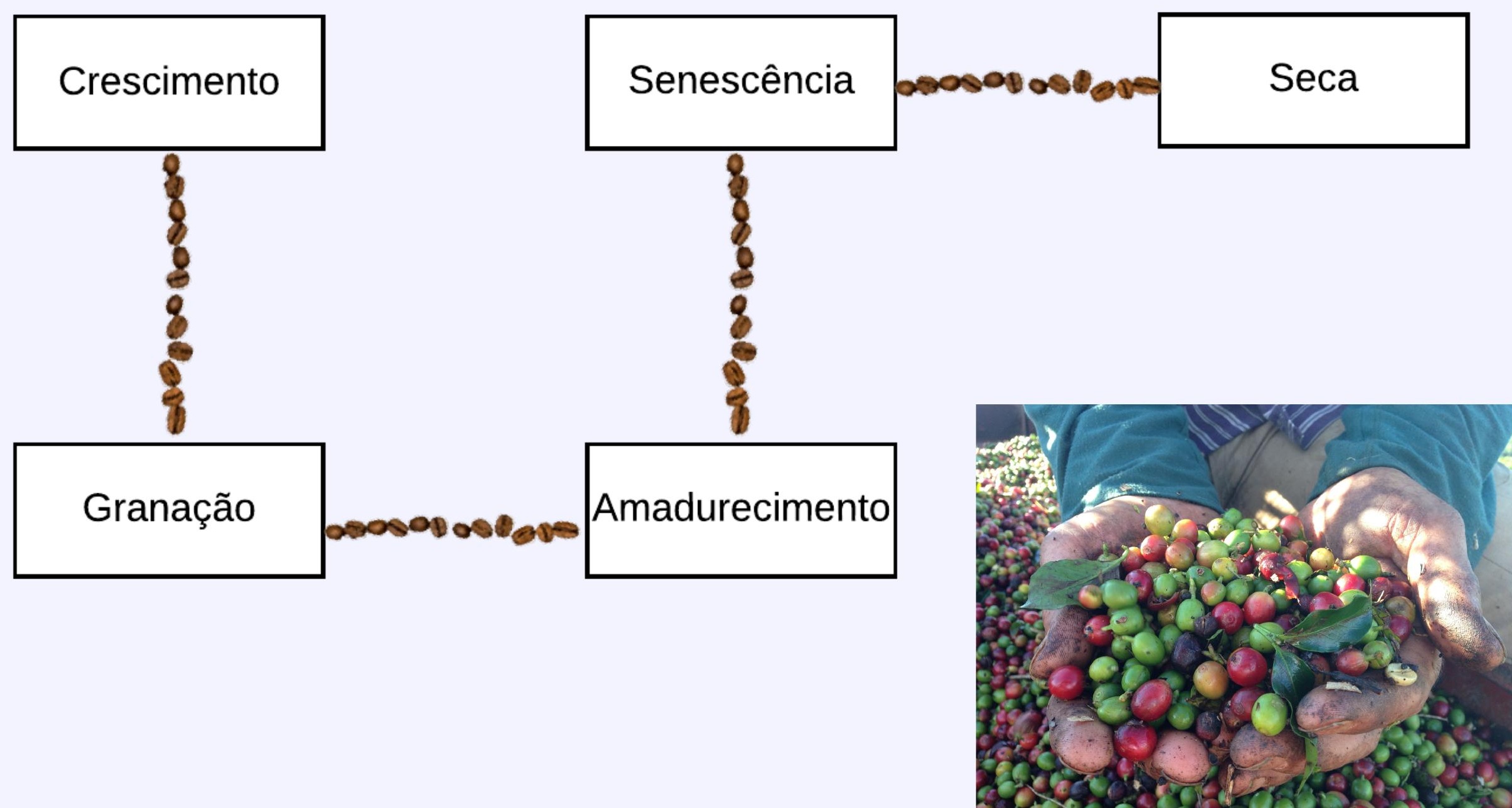




\section{$\mathbb{D D O} \mathbb{C A F E ́}$}

O fruto do cafeeiro passa por diversas fases, sendo cada uma de extrema importância para a obtenção de cerejas sadias e graúdas.

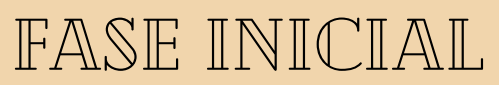

Nessa fase os frutos ficam em estágio de dormência por aproximadamente seis semanas.

\section{$\mathbb{C R E S C I M \mathbb { E N T }} \mathbb{E} \mathbb{G} \mathbb{R} \mathbb{A} A \mathbb{C} \tilde{A} \mathbb{O}$}

É um período de expansão que vai até o fruto verde atingir seu tamanho final, que tem como característica endurecimento do endocarpo. Com isso, inicia-se a formação do endosperma, ou semente, que possui um aspecto leitoso. Nessa fase, o crescimento é interrompido por um pequeno intervalo para que ocorra o endurecimento do endosperma, sendo essa a granação.

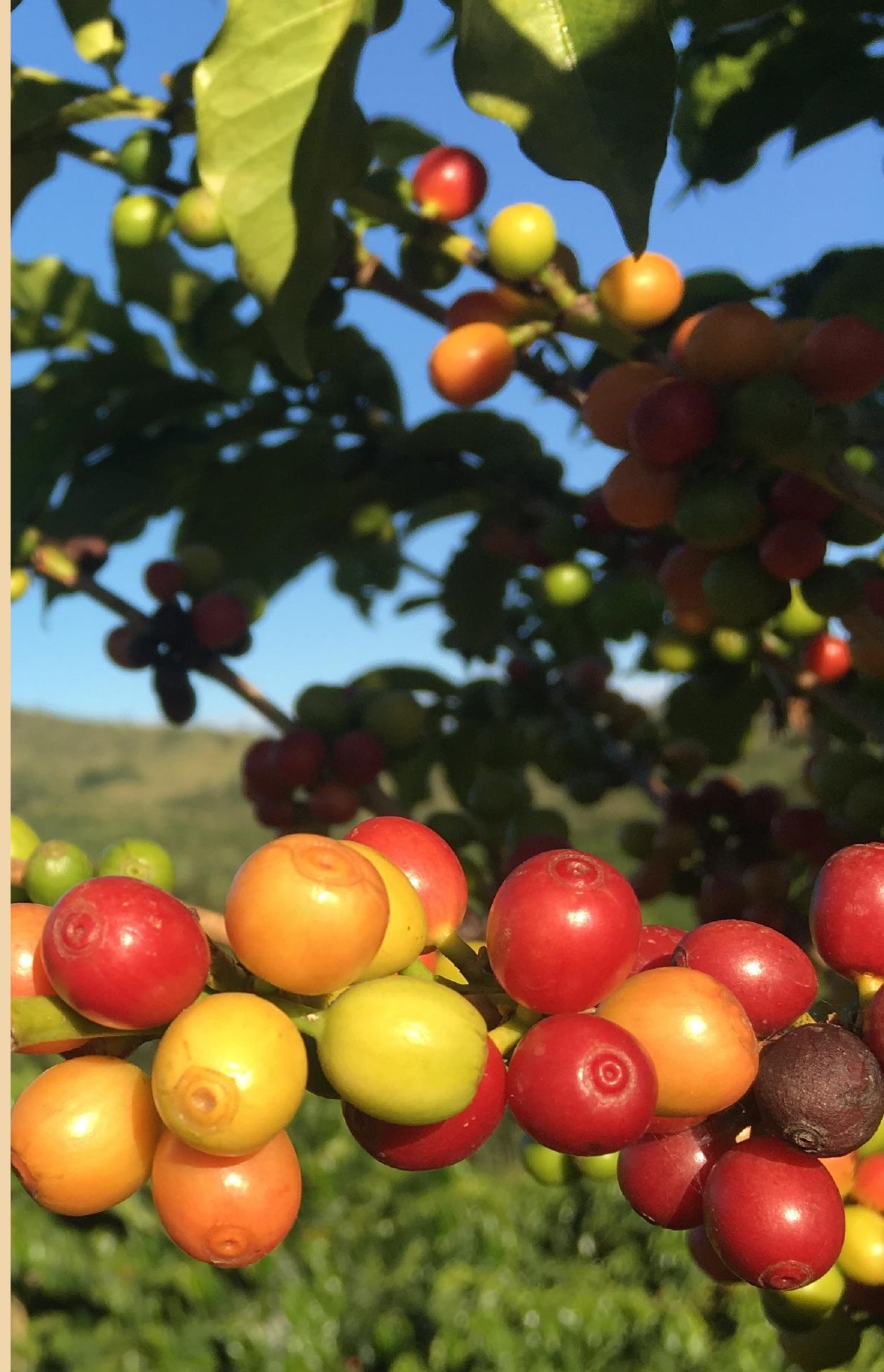




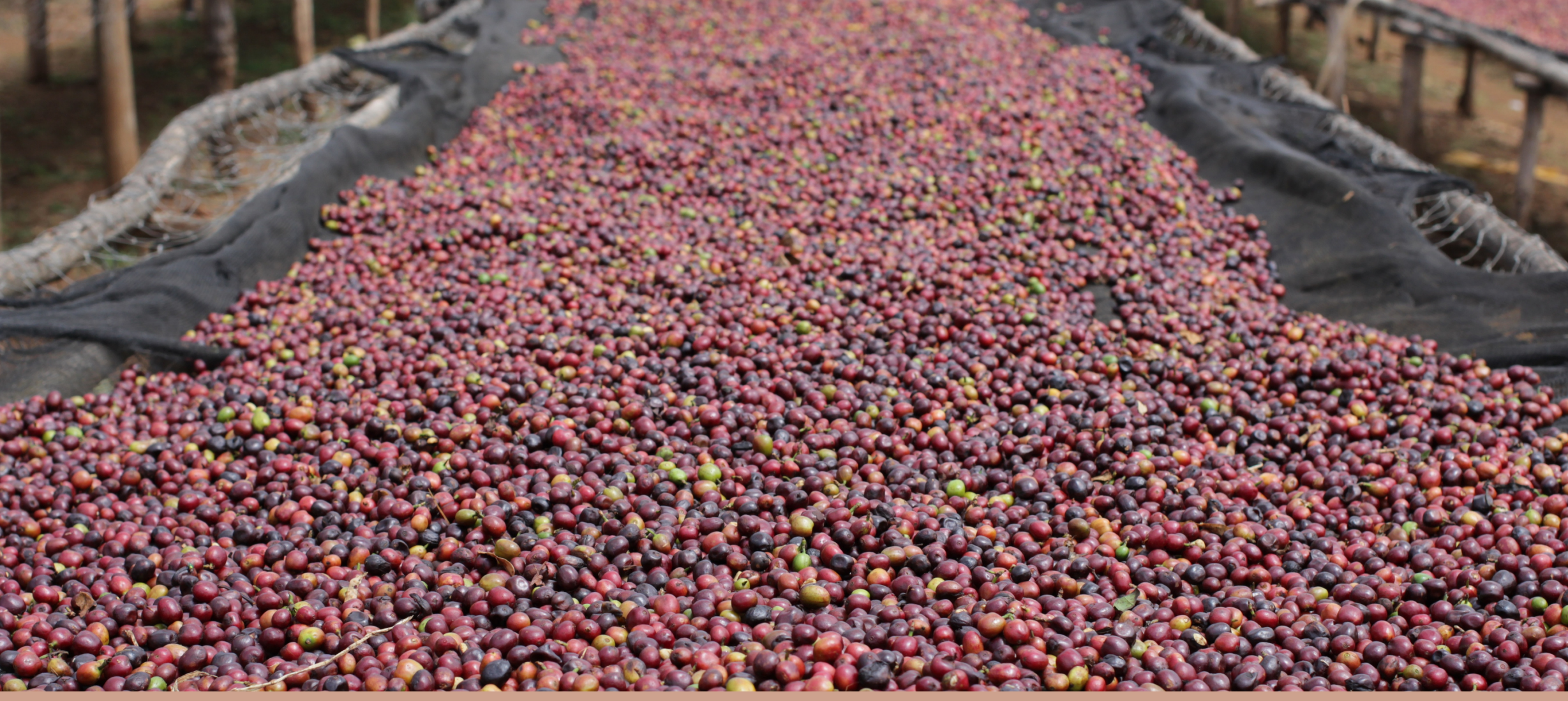

Depois da granação o fruto adquire uma cor verde-cana, que evolui para o vermelho ou amarelo, dependendo do cultivo. Nesse momento há alterações nos ácidos e compostos fenólicos que são responsáveis pela adstringência do fruto verde, além de um aumento da síntese de açúcares.
Após a maturação começa a senescência do café e a seca gradativa da mucilagem, sendo essa uma secreção rica em carboidratos que retém água e aumenta o volume do fruto. 


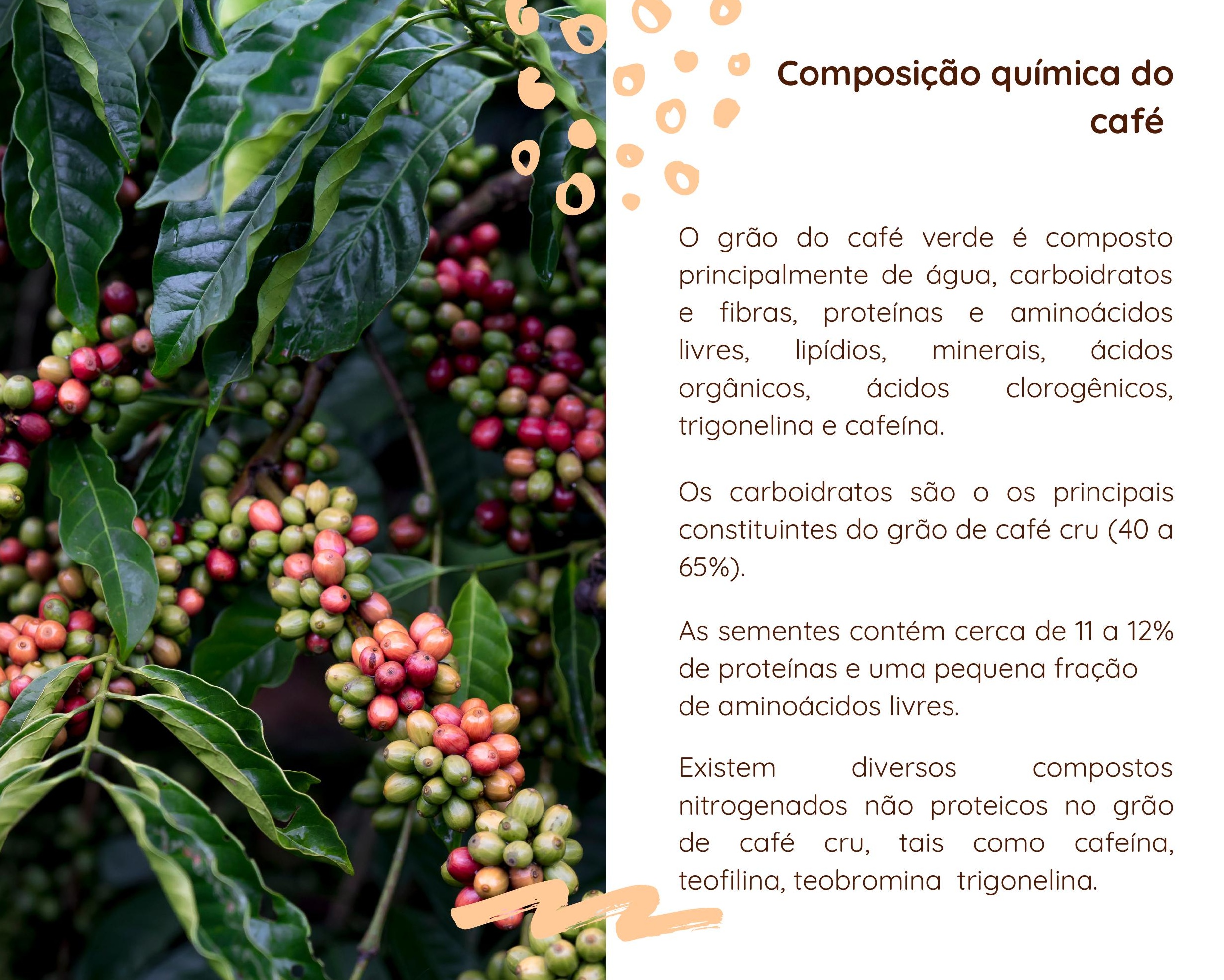


Valor nutricional do café em pó torrado

\begin{tabular}{|c|c|c|}
\hline & Unidade & $\%$ \\
\hline Energia & Kcal & 326 \\
\hline Carboidratos totais & $\mathrm{g}$ & 65,8 \\
\hline Proteínas & $\mathrm{g}$ & 14,7 \\
\hline Lipídios & $\mathrm{g}$ & 11,9 \\
\hline Fibra alimentar & $\mathrm{g}$ & $\mathbf{5 1 , 2}$ \\
\hline
\end{tabular}

Valor nutricional da bebida café, infusão 10\% sem açúcar

\begin{tabular}{|c|c|c|}
\hline & Unidade & $\%$ \\
\hline Energia & Kcal & 10 \\
\hline Carboidratos totais & $\mathrm{g}$ & 1,68 \\
\hline Proteínas & $\mathrm{g}$ & 0,67 \\
\hline Lipídios & $\mathrm{g}$ & 0,07 \\
\hline
\end{tabular}




\section{ÁCIDOS CLOROGÊNICOS}

Os ácidos clorogênicos conferem adstringência, amargura e acidez à bebida de café.

Eles são responsáveis por grande parte da atividade antioxidante do café, na proporção de 7 a $10 \%$, isto é, três a cinco vezes mais que a cafeína, e ainda 'possui potencial atividade antibacteriana, antiviral, e anti-hipertensiva.

Eles estõa mais concentrados no café verde e suas concentrações reduzem drasticamente com a torrefação dos grãos.

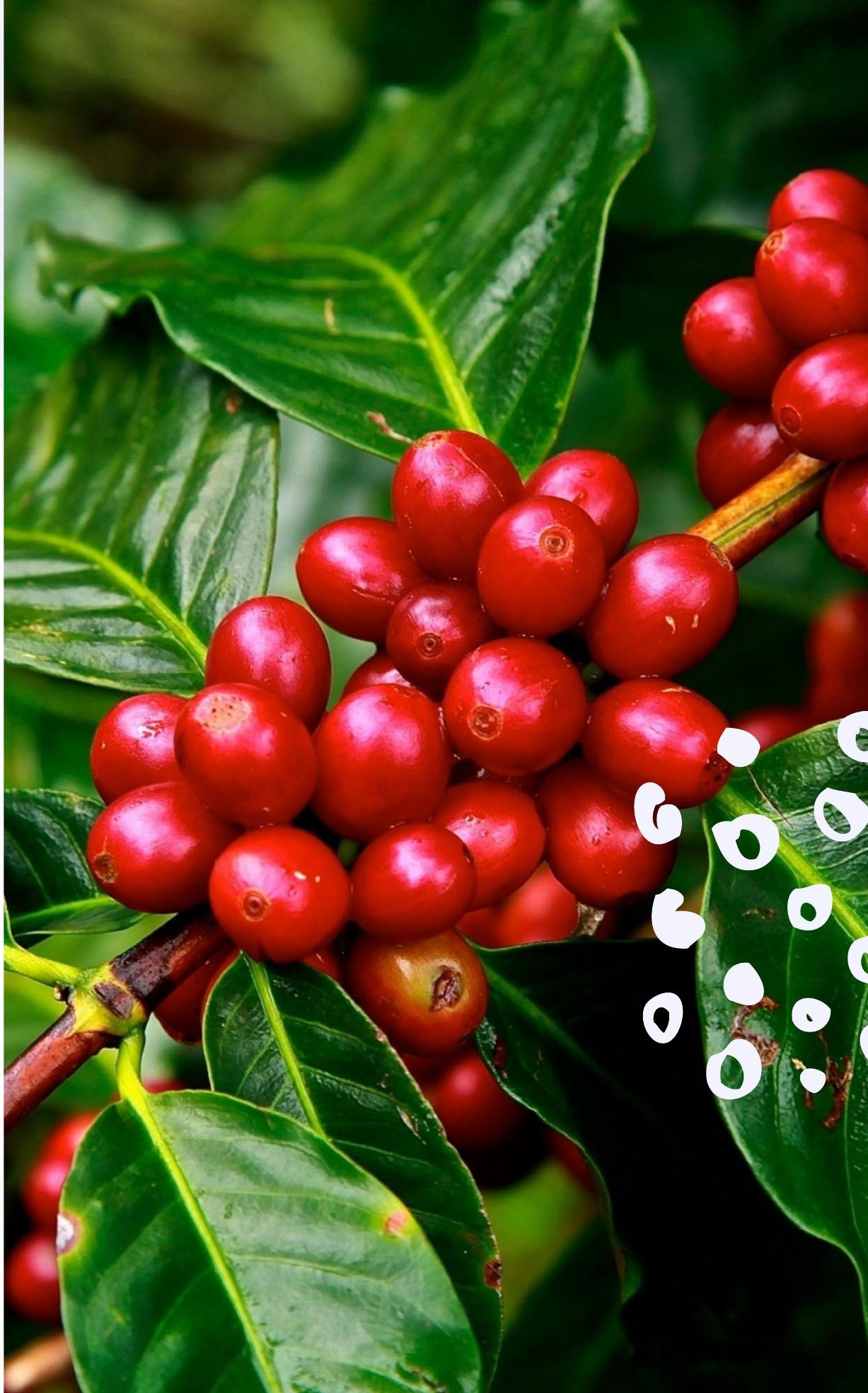




\section{TRIGONELINA}

(1) Contribui para a amargura da bebida e é - um precursor para a formação de ( diferentes classes de compostos voláteis - durante a torrefação, como pirrois e piridinas.
A desmetilação da trigonelina durante a torrefação de café produz o ácido nicotínico, a vitamina do complexo B3, também conhecida como niacina.

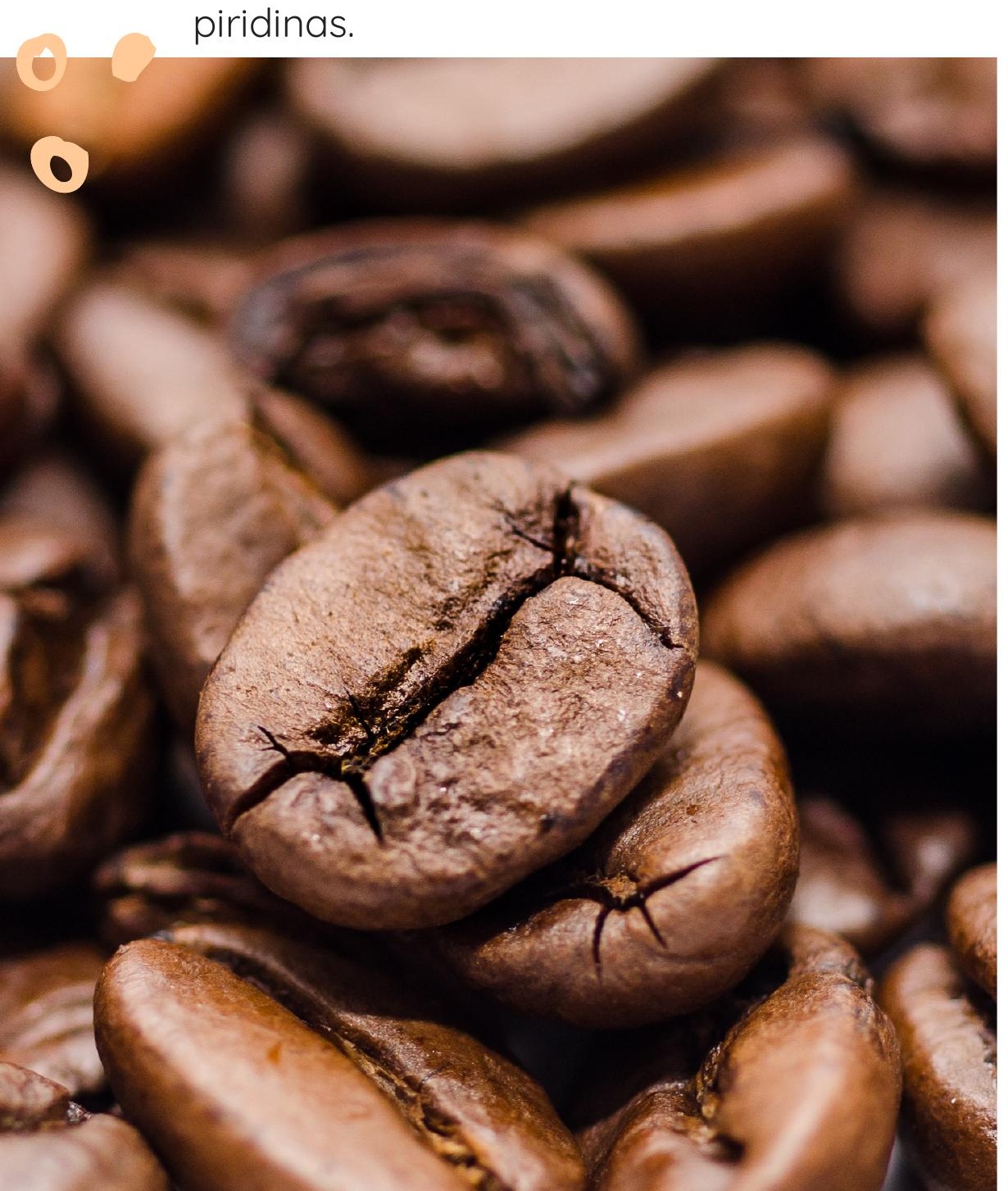


Fatores que alteram a qualidade do café

Diversos fatores podem alterar a qualidade, tais como: fatores genéticos, ambientais, nutricionais, manejo da lavoura, colheita, preparo, etc. Dentre eles, só os fatores genéticos e ambientais não podem ser controlados através de boas práticas agronômicas.

\section{Fermentação}

Os microrganismos podem alterar sabor e aparência dos frutos mediante sua fermentação natural dependendo das condições de cultivo (altitude, umidade relativa do ar), das defesas agrícolas empregadas, da colheita e do preparo. 


\section{Queda prematura}

\section{Formação}

A incidência de doenças, o déficit hídrico, a deficiência nutricional podem gerar a queda prematura do grão de café.

Durante o crescimento e a granação estiagens prolongadas, temperatura elevada, deficiência nutricional, podem prejudicar $\mathrm{o}$ desenvolvimento dos frutos, fazendo com que apareçam grãos cochos e mal granados.

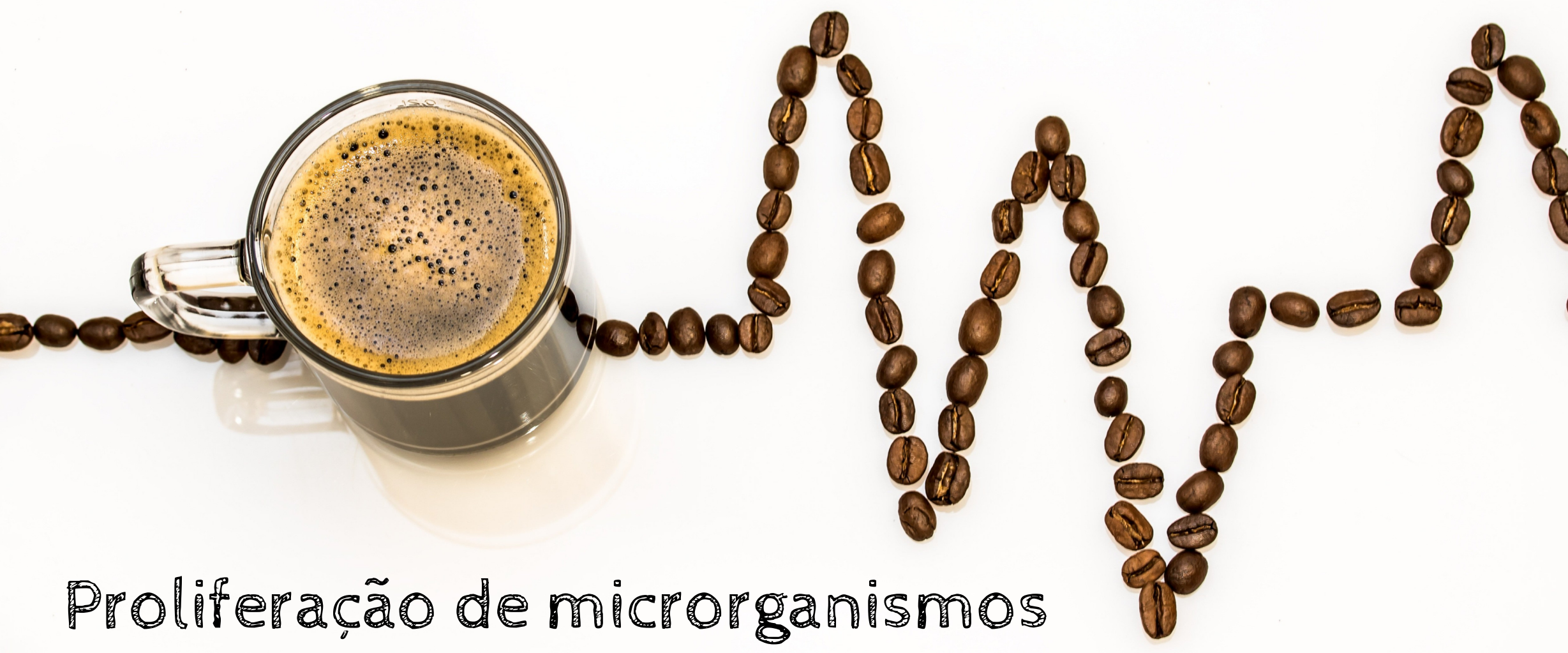

Durante a senescência e seca, a umidade relativa do ar pode contribuir para a proliferação de microrganismos nos grãos de café, tanto em frutos na planta quanto naqueles já caídos. 
0
00
00
0
0

\section{Alterações}

\section{químicas}

A infusão do café é um produto de complexa composição química, principalmente após sua torrefação, onde os compostos originais do grão são degradados e novos compostos são formados garantindo a presença de substâncias nutritivas, bioativas e suas características de sabor e aroma.

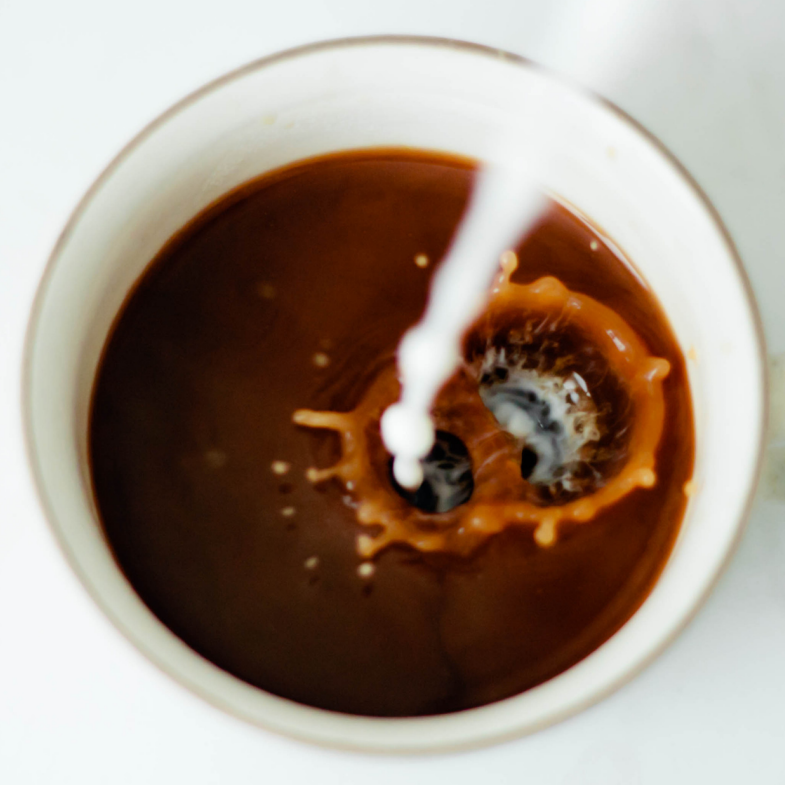




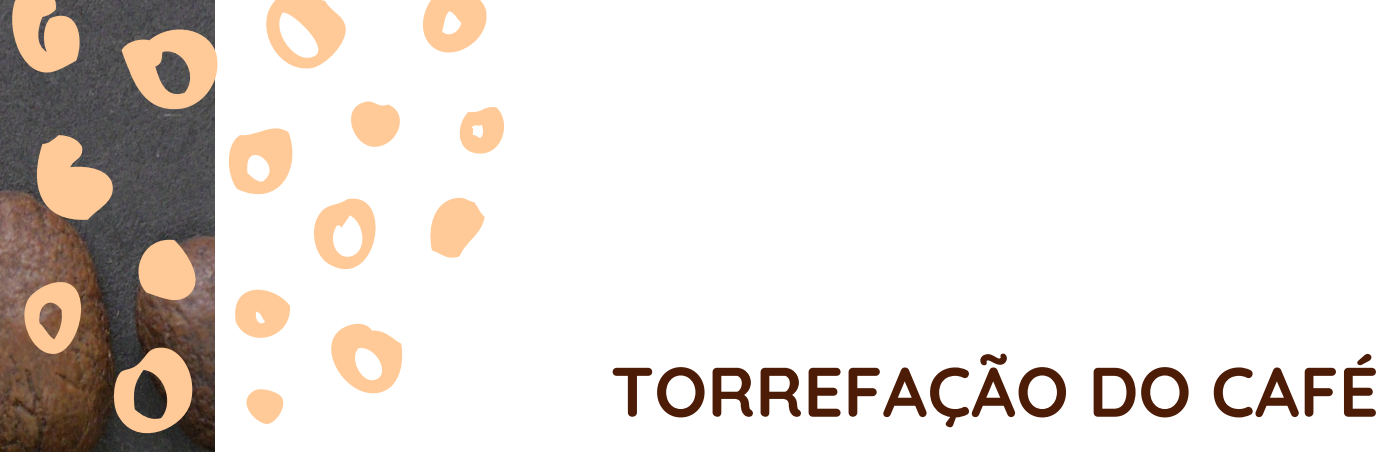




\section{MELANOIDINAS}

(1) As altas temperaturas observadas no

(1) processo de torra levam à formação de compostos castanhos poliméricos e de alto

- peso molecular, denominado de

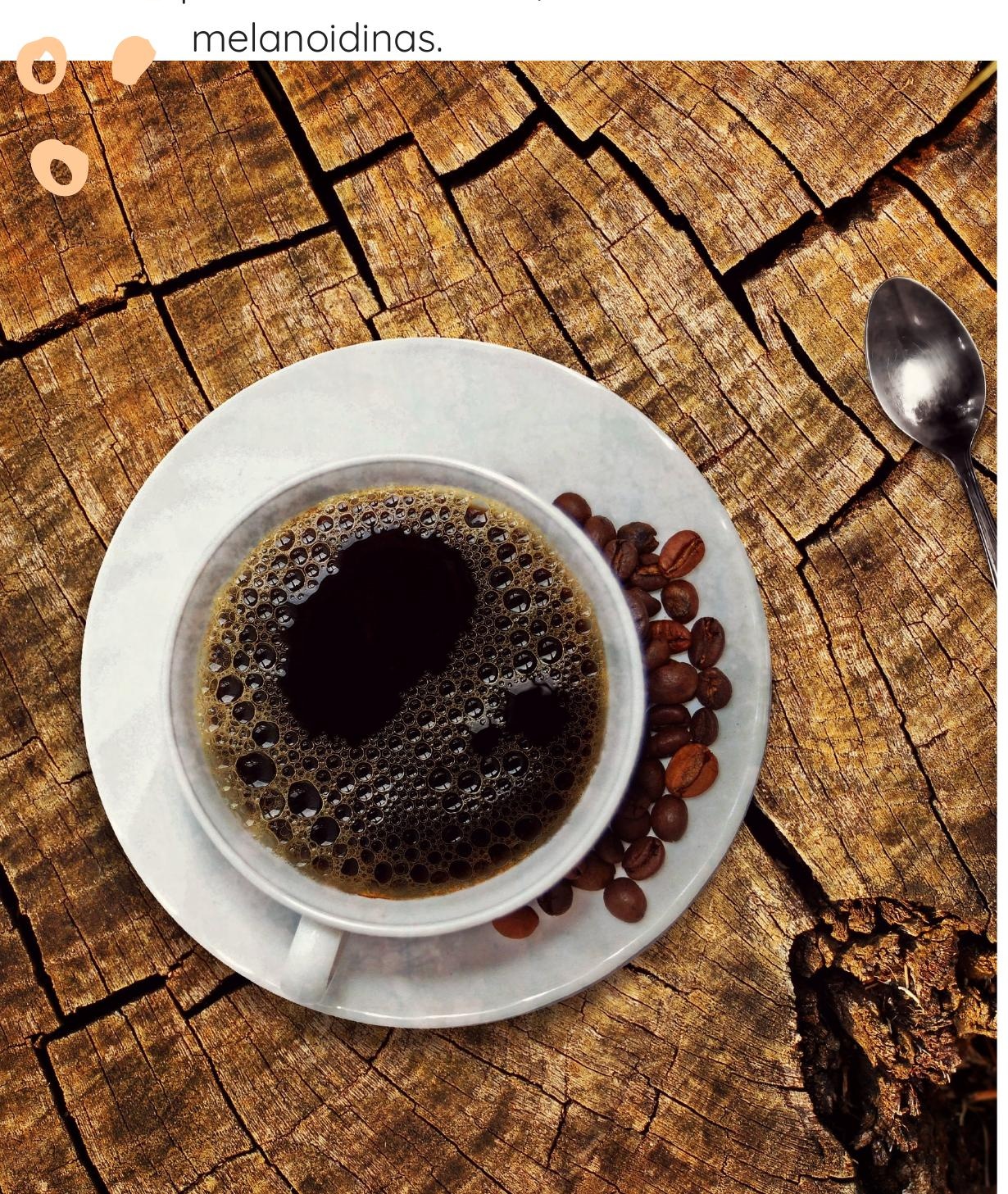

Estas substâncias possuem atividade antioxidante, antimicrobiana e anti-hipertensiva. Quanto mais escuro o grau de torrefação, maior a quantidade de melanoidinas presentes na bebida e sua complexidade estrutural.

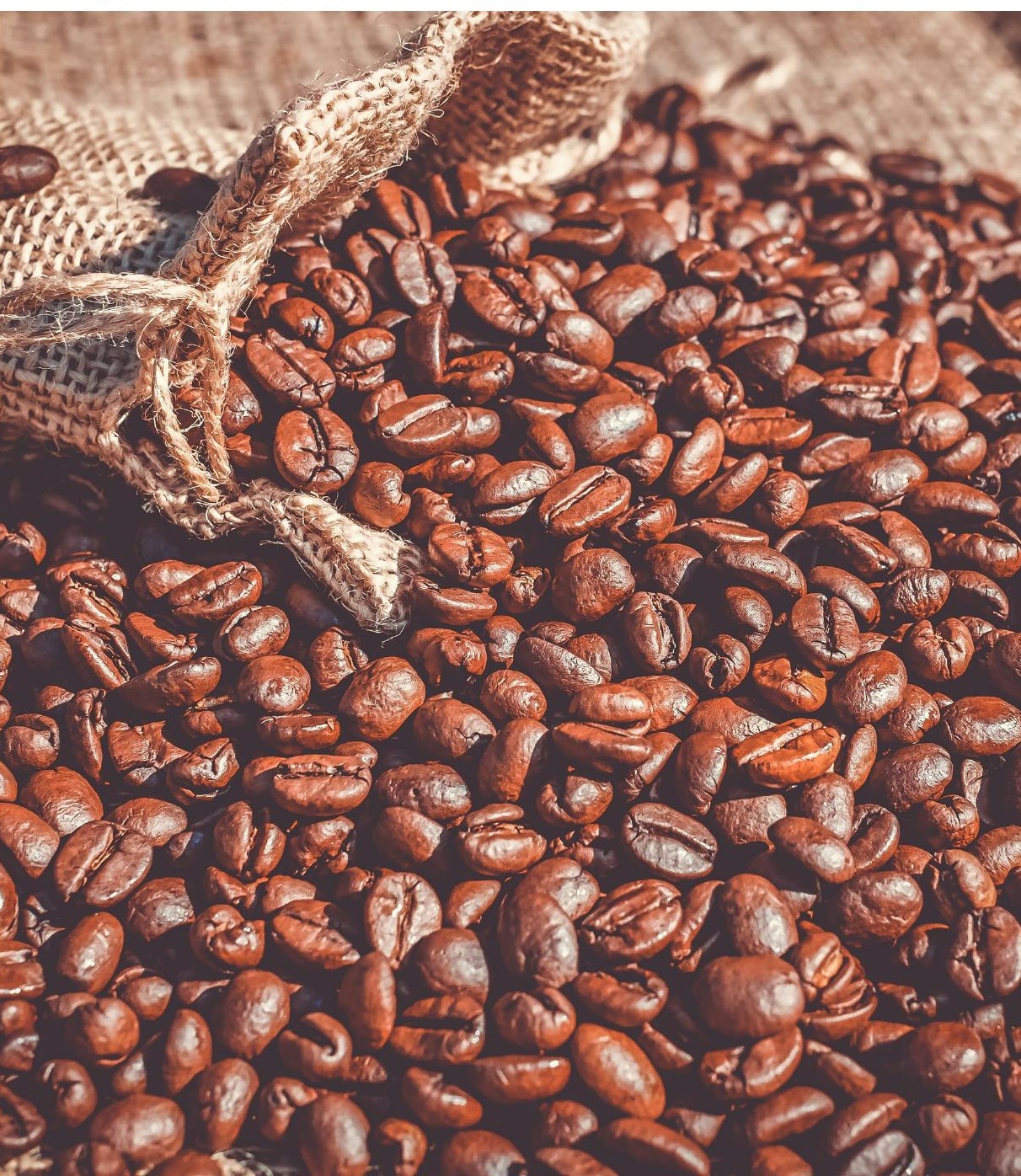






\section{Jepos de preparo}

A adição de água quente ao café torrado e moído, produzindo então a bebida café, é um processo chamado de infusão, e pode ocorrer por filtragem, percolação, prensagem ou pressão, sendo que cada um destes produz tipos de bebidas distintas.
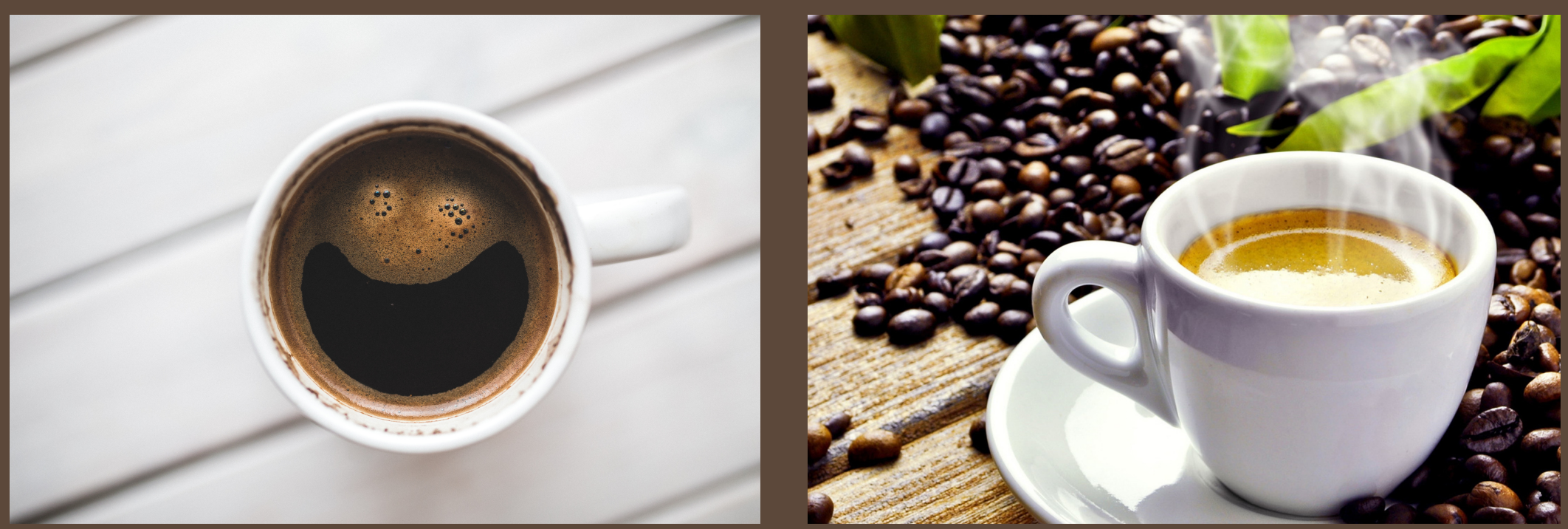

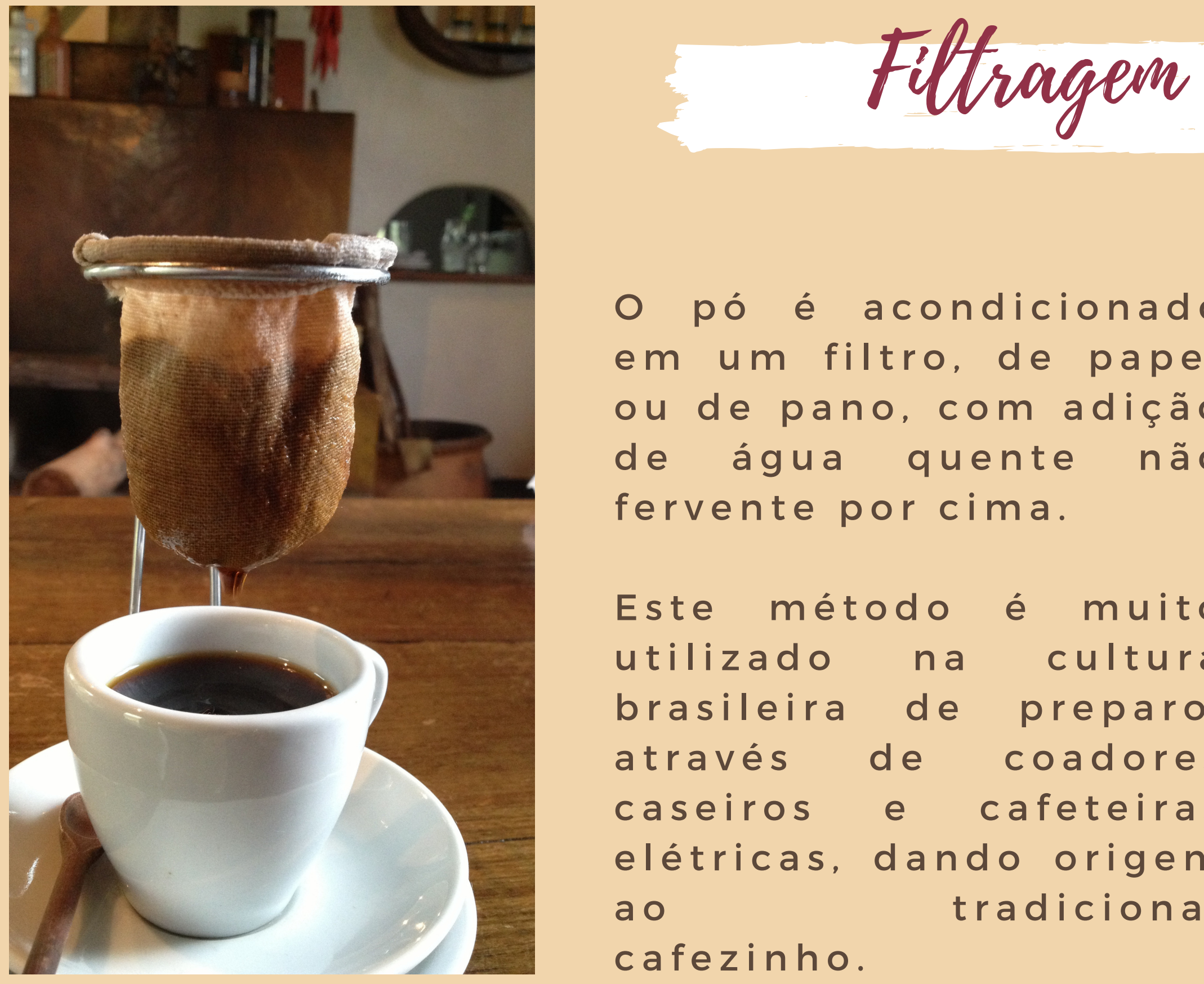

- pó é acondicionado em um filtro, de papel ou de pano, com adição de água quente não fervente por cima.

Este método é muito utilizado na cultura brasileira de preparo, através de coadores caseiros e cafeteiras elétricas, dando origem a o tradicional cafezinho. 


\section{Percolacão}

Método onde se coloca o pó de café no centro de um equipamento moka que, posicionado na chama do fogão, faz a água, que está na parte inferior, entrar em ebulição e pressionar o café líquido para um recipiente.

É a forma mais utilizada para consumo de café na Europa.

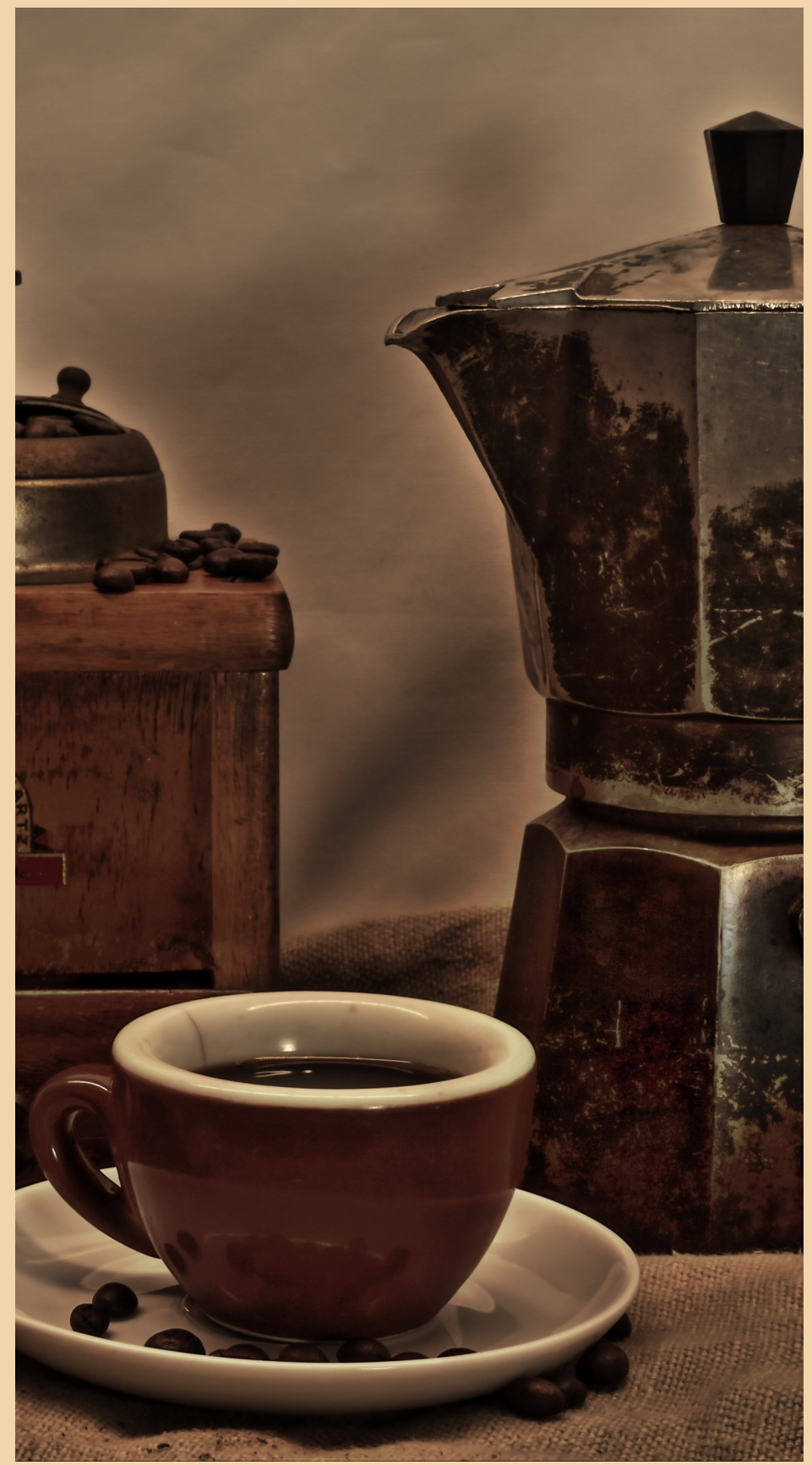




\section{Prensagem}

Em um recipiente de vidro se coloca o pó de café misturado com água quente não fervente e em seguida introduz-se um filtro que é pressionado por um êmbolo que separa o pó do café já pronto para consumo.

- método, que virou moda entre os norte-americanos, é conhecido como Prensa Francesa.
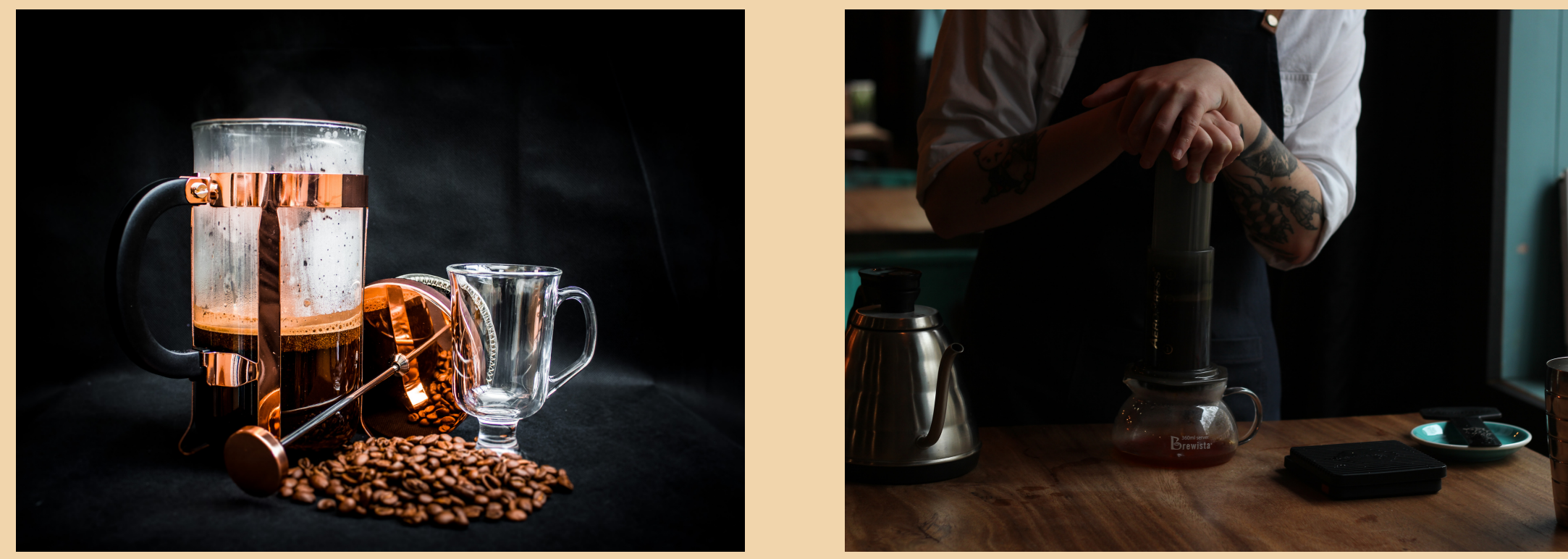


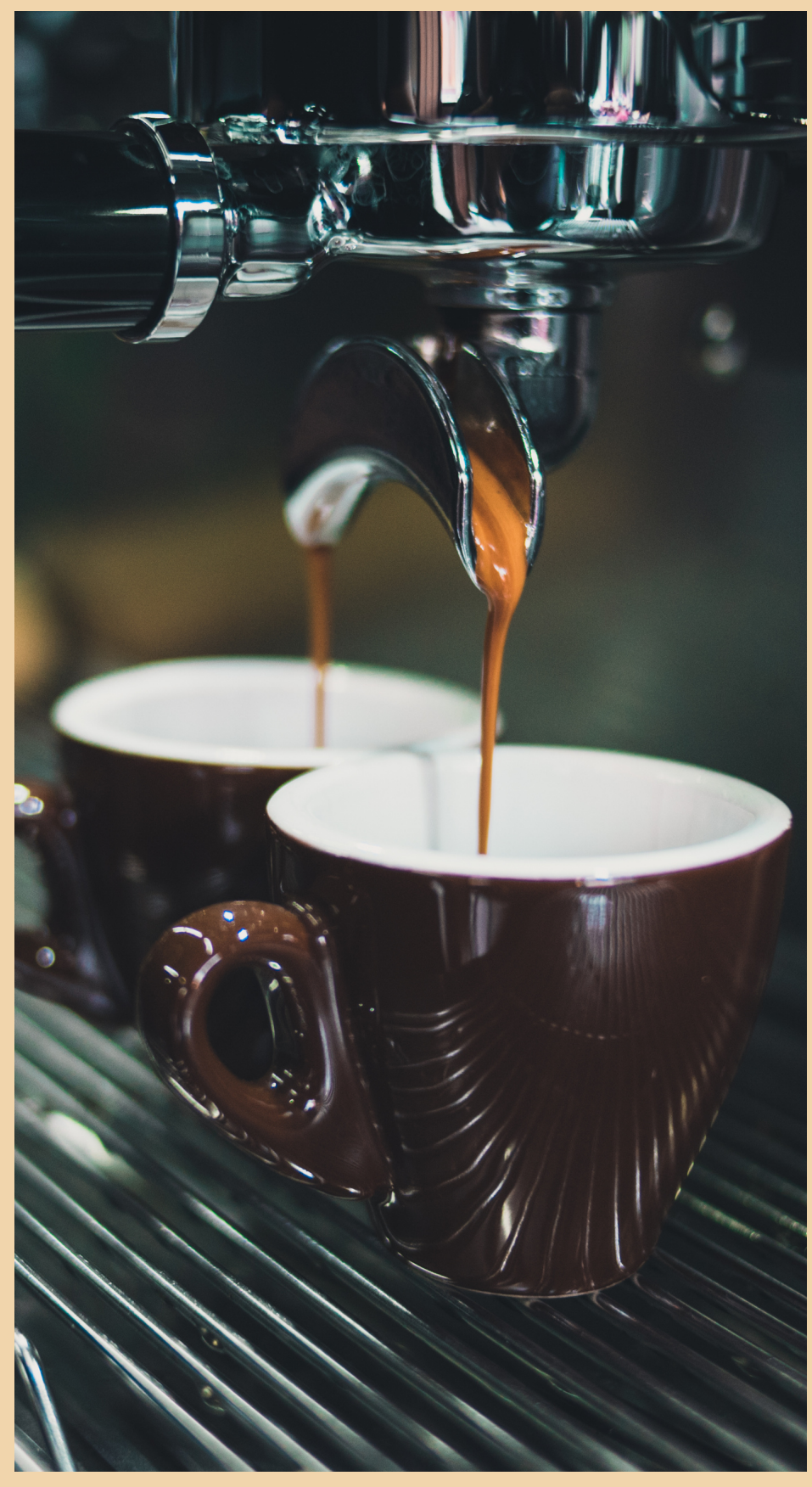

\section{Pressão}

Conhecido

como

c a fé expresso, neste preparo o café é moído na hora e acondicionado em um filtro que sofre uma pressão de água a $90^{\circ} \mathrm{C}$ e 9 $\mathrm{Kg}$ de pressão durante 30 segundos e $m$ gerando u ma média, cremosa e aromática.

Criado pelos franceses, o c a fé expresso bebida considerado o mais apropriado método apreciação de todas as nuances desta bebida. 
(1) O café é o queridinho do dos brasileiros, mas - ainda há muita controvérsia sobre os benefícios e - malefícios à saúde.

6
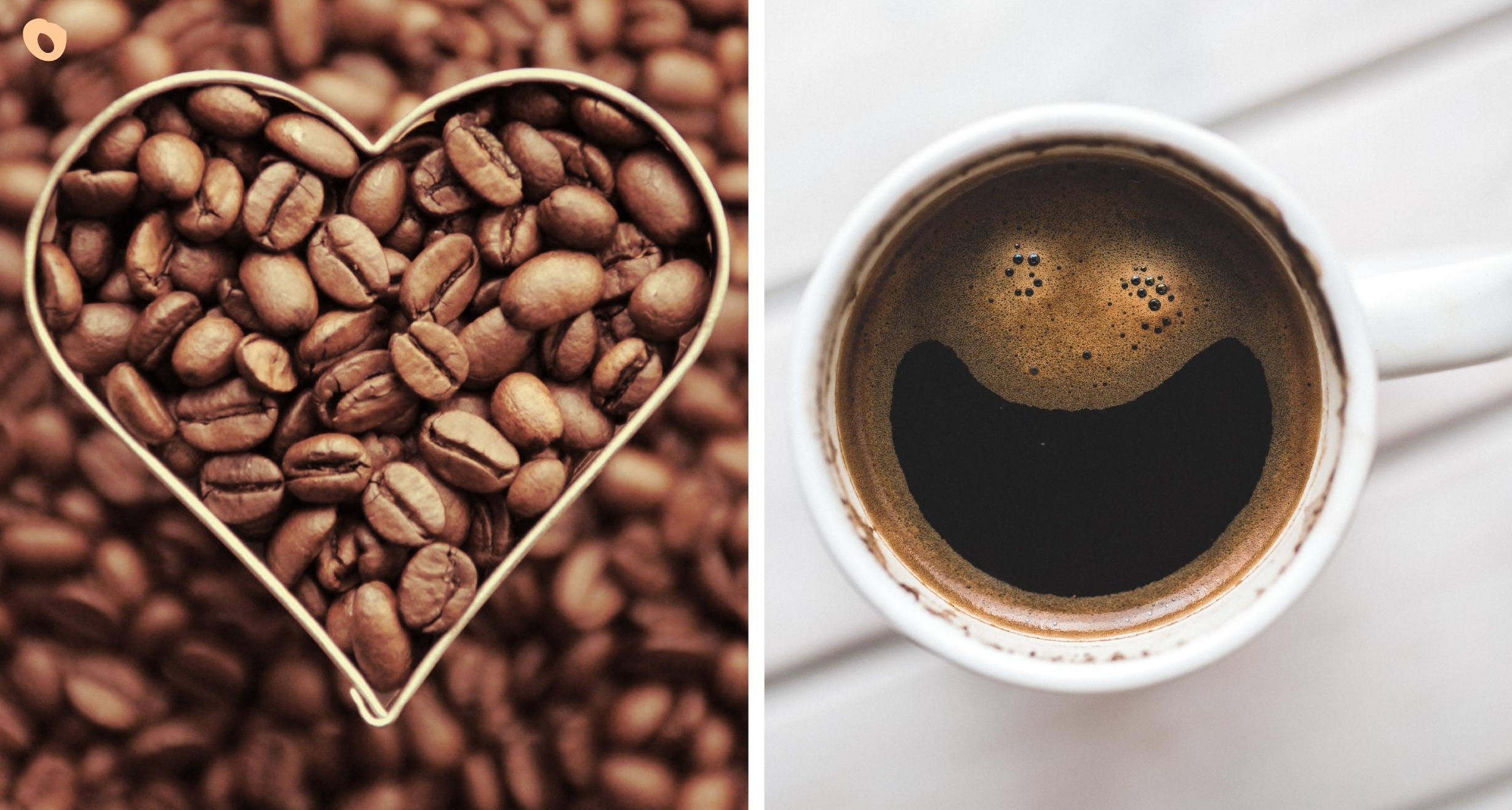
Beneficiog

Seu consumo está associado a menor risco de doenças crônicas como doenças cardiovasculares, diabetes do tipo 2, câncer e Alzheimer.

consumo de café melhora o estado de alerta, aprendizado, humor e performance no exercício físico.

Seu consumo deve estar associado à hábitos de vida saudável! 


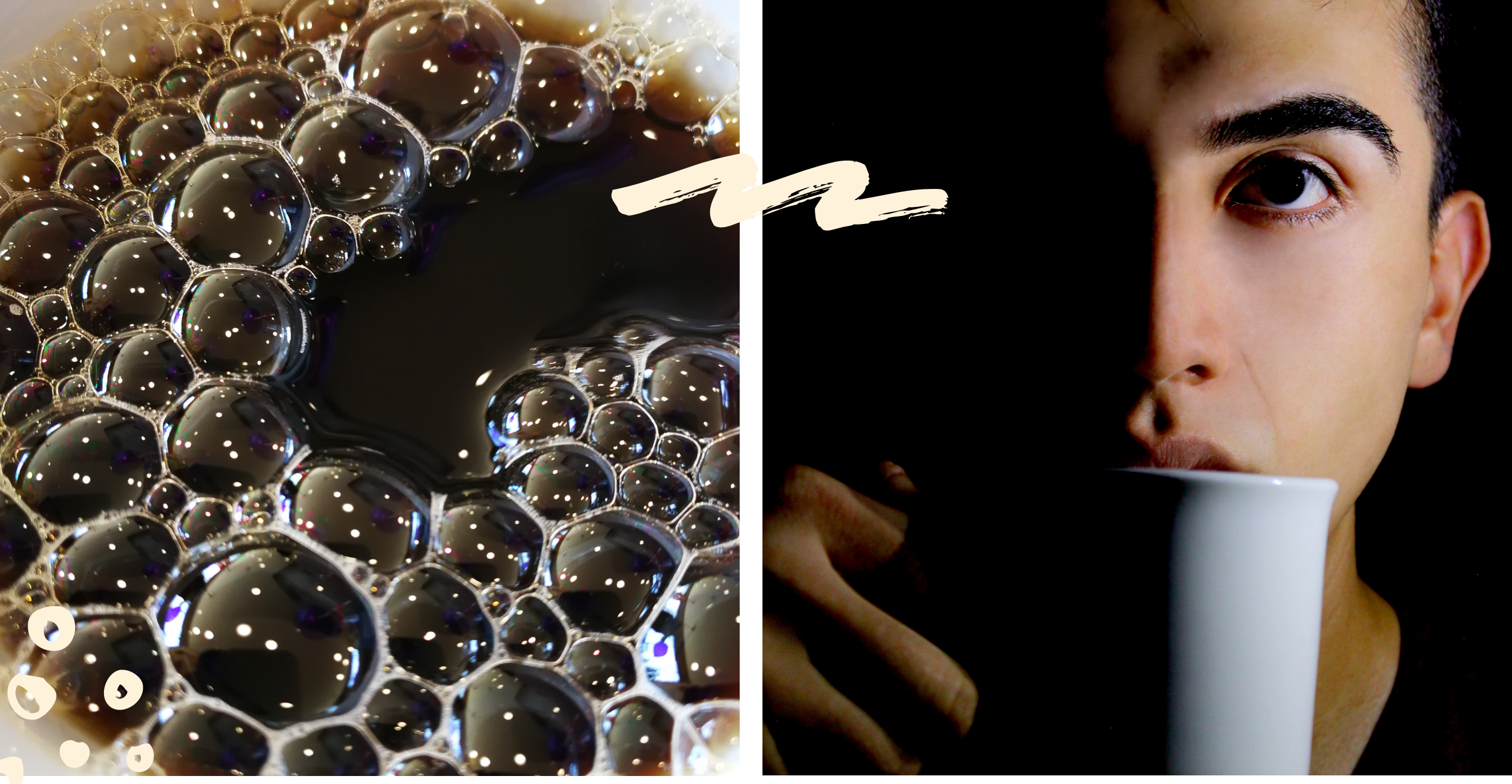

\section{ATENÇÃO!!!}

O consumo a noite deve ser evitado pois pode prejudicar o sono.

O consumo deve ser evitado por gestantes, mulheres que amamentam e crianças menores de 2 anos.

Pessoas com gastrite, úlceras, refluxo e arritmias cardíacas devem consultar seu médico ou Nutricionista para avaliar o consumo.

O seu consumo sem coar ou o pó fervido na água pode concentrar substancias tóxicas como a acrilamida.

Nunca tome suplementos de cafeína por conta própria, pode trazer prejuízos à sua saúde, consulte o Nutricionista para suplementação. 
Referências:

1. Associação Brasileira da Indústria de Café. Disponível em: <https://www.abic.com.br>. Acesso em 27 de abril de 2020.

2. Tabela Brasileira de Composição de Alimentos. Disponível em: <http://www.tbca.net.br/>. Acesso em 27 de abril de 2020.

3. MESQUITA, CM de et al. Manual do café: colheita e preparo (Coffea arábica L.). Belo Horizonte: EMATER-MG, 2016.

4. Klobitz, Maria Gabriela Bello. (2011). Café, cacau e chá. In Klobitz, Maria Gabriela Bello. Matérias-primas alimentícias: composição e controle de qualidade. Rio de Janeiro: Guanaraba Koogan.

5.Farah, Adriana. et al. (2012). Coffee constituints. In: Chu, Y. Coffee: Emerging Health Effects and Disease Prevention, First Edition. Istitute of Food Technologists, cap. 2,(p. 2158).

6. Buldak, Rafal J. et al. (2018). The Impact of Coffee and Its Selected Bioactive Compounds on the Development and Progression of Colorectal Cancer In Vivo and In Vitro. Molecules, vol. 23, n. 12, p. 3309-3335, doi:10.3390/molecules23123309.

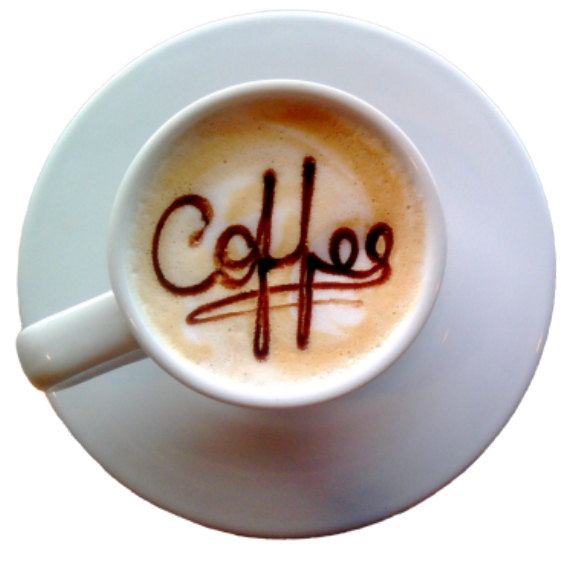

